\title{
Calculation Methods of Seepage Coefficient for Clay Based on the Permeation Mechanism
}

\author{
Yu Zhang $\mathbb{D}^{1},{ }^{1}$ Tielin Chen $\mathbb{D D}^{1}{ }^{1}$ Yujun Zhang, ${ }^{2}$ and Weizhong Ren ${ }^{2}$ \\ ${ }^{1}$ Key Laboratory of Urban Underground Engineering of Ministry of Education, Beijing Jiaotong University, \\ Beijing 100044, China \\ ${ }^{2}$ Wuhan Institute of Rock and Soil Mechanics, Chinese Academy of Sciences, Wuhan 430071, China \\ Correspondence should be addressed to Yu Zhang; zhangyu871030@163.com
}

Received 28 September 2018; Accepted 1 January 2019; Published 3 March 2019

Academic Editor: Cumaraswamy Vipulanandan

Copyright (C) 2019 Yu Zhang et al. This is an open access article distributed under the Creative Commons Attribution License, which permits unrestricted use, distribution, and reproduction in any medium, provided the original work is properly cited.

\begin{abstract}
The existing empirical methods of the seepage coefficient for clay have difficulty in parameter acquisition and are poor in calculation accuracy, and it is possible to find reasonable ones based on the mature empirical methods of coarse-grained soil. Firstly, the permeation mechanism of clay was analysed including influencing factors, spatial process, and parameter calculation, and the ineffective and effective voids were defined; then the empirical methods of clay and coarse-grained soil were summarised and listed. Secondly, clay was put equivalent to coarse-grained soil according to bound-water consolidation, and the parameter "equivalent void ratio" was introduced to establish the equivalent calculation methods. Finally, the liquid-plastic limit method determining the volume of ineffective voids was explained, and the feasibility of equivalent calculation methods was evaluated by three examples. The results show that seepage, permeation, and effective permeation are three different concepts; groundwater permeates in clay via the effective void. For certain soil, the increasing sequence of permeability coefficients is the seepage coefficient, permeation coefficient, and effective permeation coefficient. Introduction of the "equivalent void ratio" unifies the calculation of the seepage coefficient for clay and coarse-grained soil. The maximum of the bound-water content is about 0.9 time the size of liquid limit. The Mesri equation and the equivalent calculation method of Terzaghi or Curson-Karman are suitable for calculating the seepage coefficient of clay for the closest results to experimental values.
\end{abstract}

\section{Introduction}

Seepage and permeation are two different concepts; the strict definitions in this study are as follows. Seepage process has the characteristics of actual current, such as flow direction, flow amount, water pressure, and friction resistance; water fills all soil space continually, so it is called "virtual current." However, spatial coordinate functions are continuous, and a seepage field can be formed. Permeation is a motion process that occurs only via soil voids, and the spatial coordinate functions are noncontinuous. As a result, the corresponding academic terms are called the seepage coefficient, seepage velocity, permeation coefficient, and permeation velocity.

Seepage coefficient is often used for indicating the soil permeability and evaluating stability in geotechnical engineering, such as slope engineering, subgrade engineering, and tunnel and underground engineering; the correlative subjects are groundwater dynamics, fluid mechanics, seepage mechanics, etc. [1-9]. Currently, seepage coefficient is often obtained by experiment or consolidation inversion [10], while it is hard to be determined correctly for clay, and the difference between different methods is obvious [11]. Especially, disturbance to undisturbed soil is inevitable. Seepage coefficient is related to basic physical parameters, such as particle size and porosity $[3,4,7,10,11]$, so the empirical calculation methods including the above two main parameters for clay and coarse-grained soil have already been obtained based on massive experiment data. However, methods for clay, such as obtaining seepage coefficients by $\mathrm{CM}$ and Taylor, are limited to parameter acquisition and calculation accuracy $[10,11]$. Inversely, empirical methods for coarse-grained soil are relatively correct, such as 
Terzaghi, China Institute of Water Resources and Hydropower Research (abbreviated as "IWHR"), Curson-Karman, and $\mathrm{KC}$ [11]. Therefore, it is possible to find simple and correct approaches to calculate the seepage coefficient of clay based on coarse-grained soil.

Reddi and Thangavadivelu suggested one method to calculate the seepage coefficient of clay based on random network and percolation theory [2]. Liang and Fang analysed the influencing factors on seepage property for tiny clay and explained them in terms of "microelectric field" and "microsize" effects [4]. Deng found the linear positive correlation between natural logarithm of the seepage coefficient and void ratio for clay, and the gradient is about $0.5 e_{0}\left(e_{0}\right.$ is the initial void ratio) [10]. Dang et al. established the effective calculation methods of the seepage coefficient for clay based on the effective void ratio [11]. He et al. obtained the modified calculation method of the saturated seepage coefficient for bentonite based on the Poiseuille law, which includes void ratio and solution concentration $[3,12,13]$. However, the above methods are feasible under certain conditions, and they have limits in specific applications. Therefore, it is still necessary to find simple and correct calculation methods. The academic thought, research idea, and method in this study are derived from Dang's study [11].

\section{Permeation Mechanism of Clay}

In order to study the calculation method of the seepage coefficient for clay, it is very important to cognise the permeation mechanism first. Then, influencing factors, spatial process, and parameter calculation have to be analysed theoretically, thus providing fundamental works for the following study.

2.1. Influencing Factors. A soil void is interconnected, semiconnected, or sealed, and the seepage coefficient reduces with the decreasing porosity for certain soil. Generally, the seepage coefficient of clay is low for low porosity, but it is not because porosity is negatively correlated to the compactness and it is influenced by particle gradation, compaction power, and so on but not by the absolute particle size.

Here, presuming clay, silt, sand, and roundstone as round balls, their equivalent sizes are $0.002 \mathrm{~mm}, 0.02 \mathrm{~mm}$, $0.2 \mathrm{~mm}$, and $2.0 \mathrm{~mm}$. Subsequently, they are put uniformly into four cubic boxes $\left(50 * 50 * 50 \mathrm{~mm}^{3}\right)$, respectively, and then the spatial porosities are calculated, which are shown in Figure 1.

Figure 1 shows that porosities are equal for different soil particles, which are about $47.67 \%$, so they are not correlated to the absolute particle size. Therefore, the seepage coefficient of clay may be influenced by the absolute particle size under certain porosity.

Although particle size does not influence the porosity, it decides the specific surface area (shape coefficient), which are shown in Figure 2.

Figure 2 shows that the difference in specific surface area is large for different soil particles. For example, it is thousand

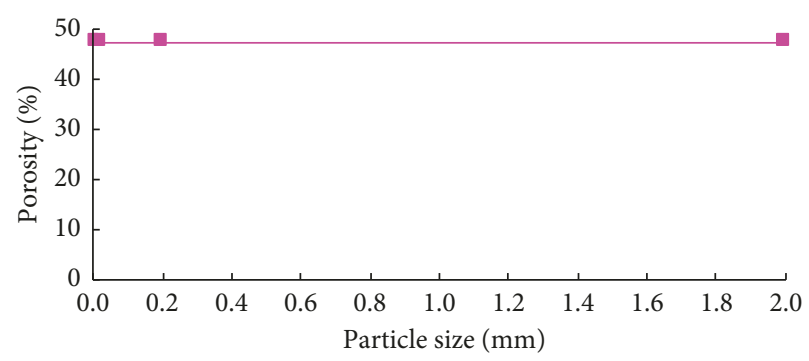

FIgURE 1: Spatial porosities for different soil particles.

times the value of particle size, that is, $2.0 \mathrm{~mm}$ for $0.002 \mathrm{~mm}$. It is negatively correlated with specific surface area and particle size, and the variation rate is larger when the particle size is small.

Large specific surface areas will cause a variety of problems, such as long permeation route, more pressure loss, high surface energy, strong adsorptivity, and large bound-water volume (shown in Table 1). However, bound water has no solvent ability, flowability, transmission of water pressure, and permeability, so it occupies partial permeation space, thus reducing the void opening perpendicular to the permeation direction. Therefore, particle size is one of the main influencing factors.

Similarly, under certain particle size and gradation, the specific surface area is a constant. Porosity can be reduced by vibration or compaction, so the permeation space will also be compressed, thus decreasing the permeability. Therefore, porosity is also one of the main influencing factors.

In summary, particle size and porosity are the main influencing factors for clay permeability. Under certain porosity, the specific surface area and bound-water volume become large when the particle size is small, so the permeation route is lengthened and void opening is reduced. On the contrary, under certain particle size, the void opening is still reduced when the porosity becomes low. Therefore, permeability of clay is influenced by the coupling of particle size and porosity.

2.2. Spatial Process. Soil consists of the solid phase, liquid phase, and gas phase, in terms of permeation space, soil particles, and permeation voids contained. It is mentioned that specific surface area and bound-water volume are low for coarse-grained soil but large for clay. In order to present the bound-water volume directly, presuming colloid, clay, silt, and silty sand as round balls, their equivalent sizes are $0.002 \mathrm{~mm}, 0.005 \mathrm{~mm}, 0.05 \mathrm{~mm}$, and $0.1 \mathrm{~mm}$. Then, putting them uniformly into four cubic boxes $\left(50 * 50 * 50 \mathrm{~mm}^{3}\right)$, respectively, bound-water porosity and residual porosity are calculated, which are shown in Figure 3.

Figure 3 shows that bound-water porosity increases with the decreasing particle size, and the variation rate becomes large when the particle size is small. It is $7.54 \%$ for the particle size $0.005 \mathrm{~mm}$, while it is only $0.38 \%$ for the particle size $0.1 \mathrm{~mm}$. Therefore, bound water in clay cannot be neglected. Based on the characteristics of bound water and effective stress principle, bound-water voids can be regarded 


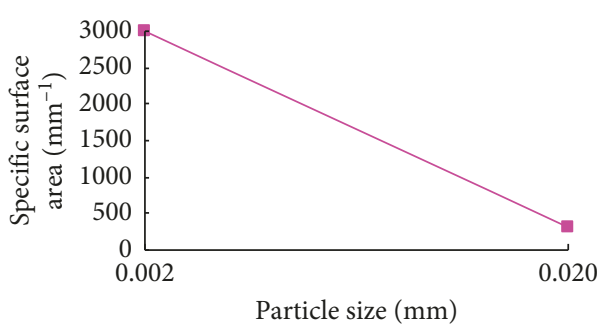

(a)

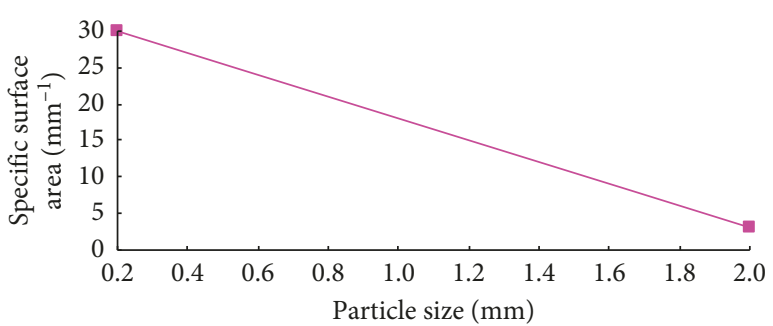

(b)

Figure 2: Specific surface areas for different soil particles with particle sizes of (a) $0.002 \mathrm{~mm}$ and $0.02 \mathrm{~mm}$ and (b) $0.2 \mathrm{~mm}$ and $2.0 \mathrm{~mm}$.

TABLE 1: Bound-water volumes for different soil particles.

\begin{tabular}{lccc}
\hline Particle size $(\mathrm{mm})$ & General surface area $\left(\mathrm{mm}^{2}\right)$ & Water-film & thickness $[14](\mu \mathrm{m})$ \\
\hline 0.002 & 196250000.00 & 0.12 & 23550.00 \\
0.02 & 19625000.00 & 0.12 & 2355.00 \\
0.20 & 1962500.00 & 0.12 & 235.50 \\
2.00 & 196250.00 & 0.12 & 23.55 \\
\hline
\end{tabular}

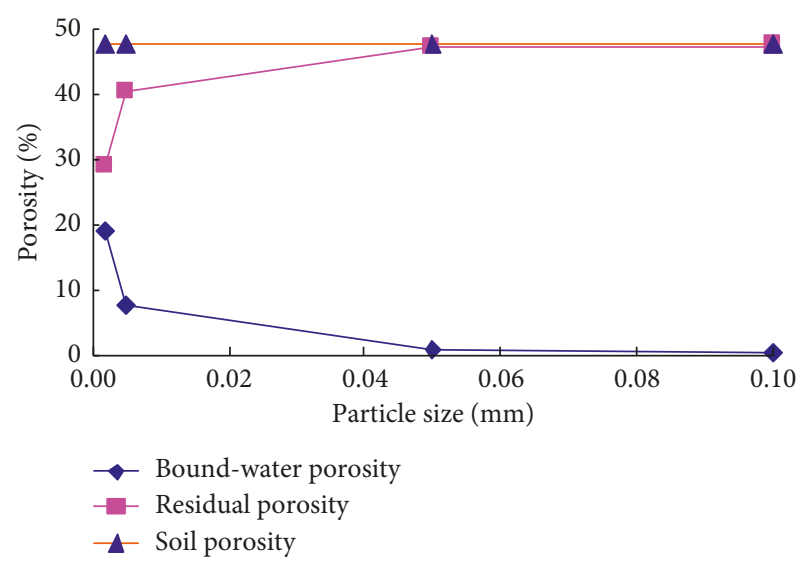

FIGURE 3: Curves of bound-water and residual porosities.

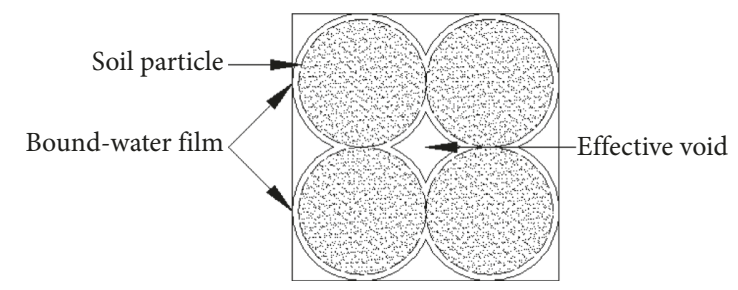

Figure 4: Bound-water film and effective void for clay.

as ineffective voids, and the residual is the effective void [11], which is shown in Figure 4.

Figure 4 shows that groundwater flows in clay via the effective void mainly, according to the concepts of seepage and permeation, and it can be called the "effective permeation," and the spatial coordinate function is also noncontinuous. Besides, the corresponding academic terms are the effective permeation coefficient and effective permeation velocity. For clay, effective permeation is the actual current, and it is not mandatory to regard permeation as the actual current without considering bound water.

2.3. Parameter Calculation. Based on the above context, seepage, permeation, and effective permeation are three different concepts. Under the same preconditions of cross section, flow direction, flow amount, water pressure, particle volume, and friction for soil, they have different explanations and applications of permeability. Although seepage is the virtual current, the value is actual. For coarse-grained soil, effective permeation is equivalent to the permeation. The calculation formulas of the permeability coefficient for the above three concepts are shown in Table 2.

Table 2 shows that $k=n k_{\mathrm{p}}=n_{\mathrm{e}} k_{\mathrm{e}}$ for certain soil, that is, $k \leq k_{\mathrm{p}} \leq k_{\mathrm{e}}$. Hence, different calculation methods of the permeability coefficient can be selected for different needs, and the seepage coefficient is widely used for continuous variables in the seepage field.

\section{Empirical Calculation Methods}

Particle size and porosity are the main influencing factors for clay permeability; accordingly, the existing empirical calculation methods $[1,10]$ including these two variables are shown in Table 3.

It can be found that the parameter particle size is not included in the CM or Taylor equation because it is certain when established, so the limit is inevitable. Furthermore, parameters in the formulas are difficult to be acquired. Although there is no particle size parameter in the Mesri equation, $C_{\mathrm{F}}$ and $A_{\mathrm{c}}$ are included, so it still indicates the significant influence caused by clay and colloid particles.

For coarse-grained soil, the empirical formulas [11] are often used to calculate the seepage coefficient in engineering practice, which are shown in Table 4. 
TABle 2: Calculation formulas of the permeability coefficient for different concepts.

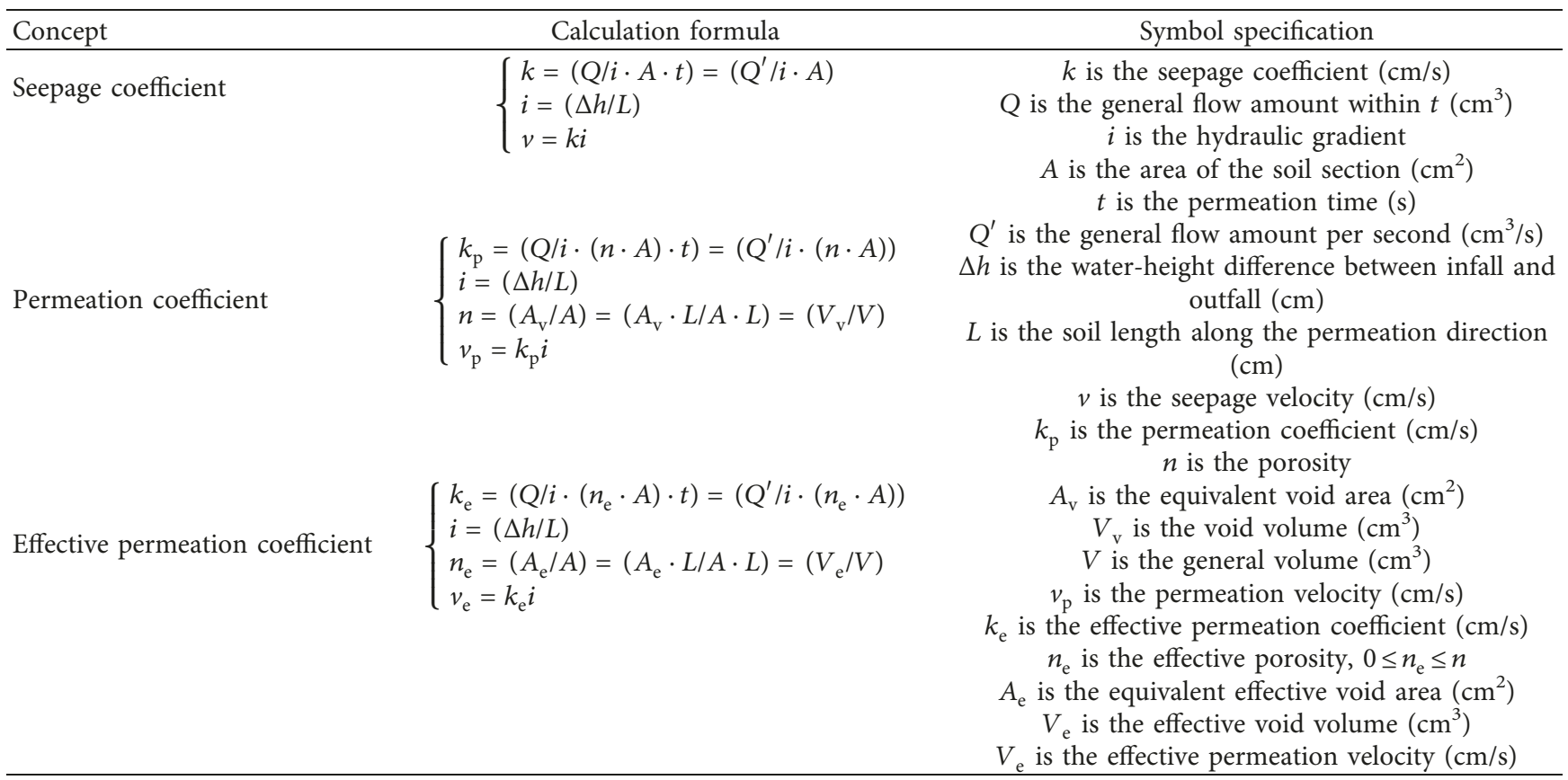

TABLE 3: Existing empirical calculation methods of the seepage coefficient for clay.

\begin{tabular}{lcc}
\hline Soil sample & Empirical calculation method & Symbol specification \\
\hline Sand, clay, and soft clay & $k=c e^{y}(\mathrm{CM}$ equation) & $c$ and $C^{\prime}$ are the dimensionless coefficients \\
& $k=C^{\prime}\left(e^{m} / 1+e\right)$ (Taylor equation) & $y$ the void ratio \\
are the empirical exponents, and $m$ is 5.0 \\
Soft clay & $k=6.54 \times 10^{-11}\left(\left(e / C_{\mathrm{F}}\right) / A_{\mathrm{c}}+1\right)^{4}$ (Mesri equation) & $\begin{array}{c}C_{\mathrm{F}} \text { is the content of clay particles } \\
A_{\mathrm{c}} \text { is the activity coefficient } \\
\text { The others are the same as given above }\end{array}$ \\
\hline
\end{tabular}

TABLE 4: Existing empirical calculation methods of the seepage coefficient for coarse-grained soil.

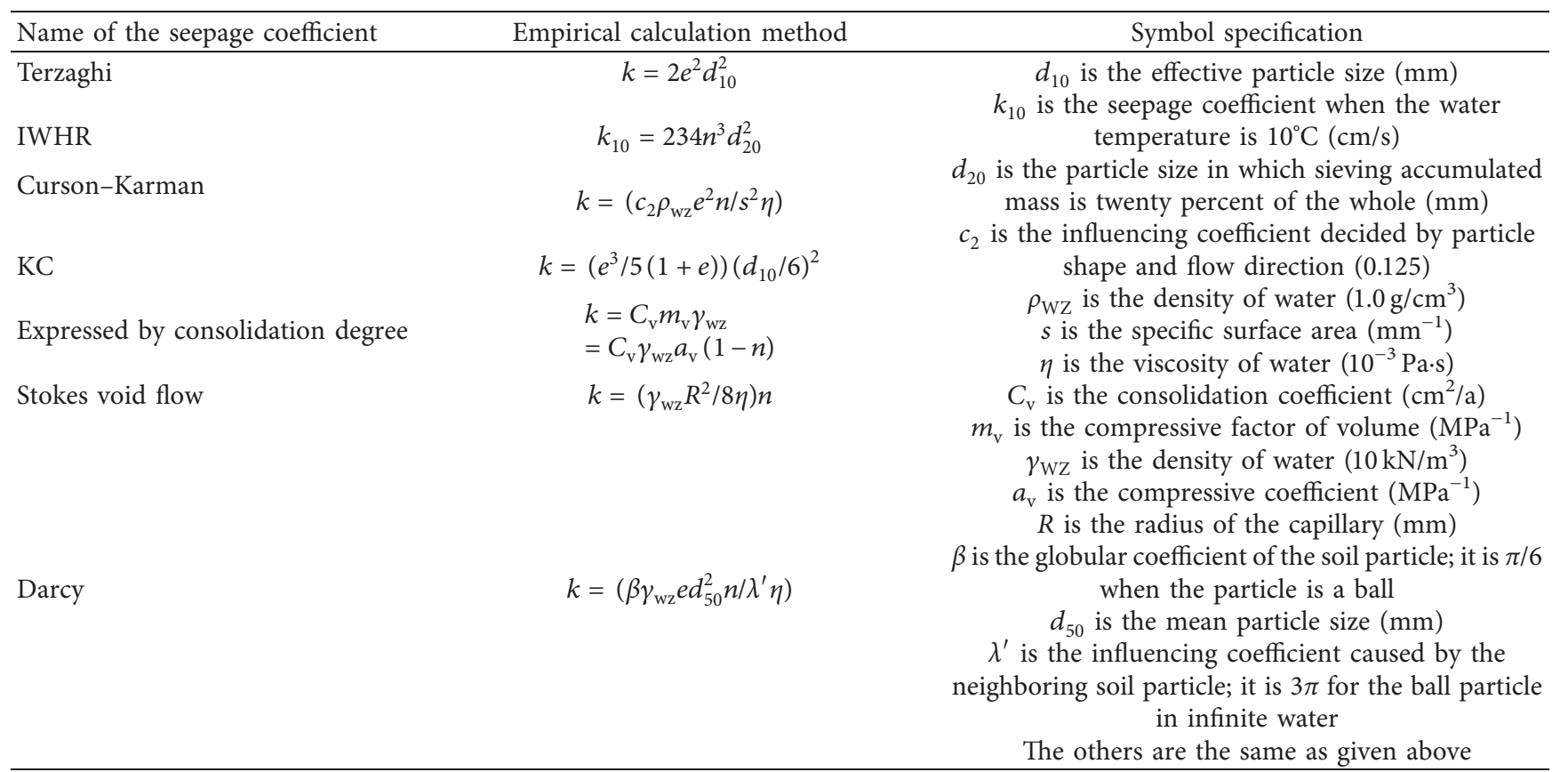


Table 4 shows that the empirical calculation methods for coarse-grained soil include particle size and porosity simultaneously and also the other influencing factors. Hence, some parameters are still difficult to be obtained, so the widely used five methods are Terzaghi, IWHR, CursonKarman, KC, and Stokes void flow [11]. According to the actual situation, the former four methods and Mesri equation of the seepage coefficient for clay are selected for use.

In summary, empirical calculation methods of the seepage coefficient for clay are limited for problems on influencing factors and parameter acquisition, while those for the coarse-grained soil are considerable and relatively easy. Therefore, it is significant to find calculation methods for clay based on the methods for coarse-grained soil. Dang et al. explored the effective calculation methods for clay based on "effective void ratio," and they found the calculation value and experimental result had the same order of magnitude. This is one new approach [11]. In this study, equivalent calculation methods of the seepage coefficient for clay will be studied based on bound-water "consolidation" and "equivalent void ratio."

\section{Equivalent Calculation Methods of Seepage Coefficient for Clay}

In order to regard clay as coarse-grained soil, it is important to make it have the same or similar soil structure and permeation mechanism. Groundwater permeates in clay via the effective void mainly, while it permeates through the whole in coarse-grained soil. Therefore, if the bound water in ineffective voids can be regarded as "solid soil," particle size of clay will increase and the permeation mechanism will also be consistent with coarse-grained soil. Hence, the equivalent principle consolidates the bound water in clay, regarding it as "solid soil."

4.1. Equivalent Calculation Methods. The equivalent calculation method has to be established under bound-water "consolidation," so the main parameter values will vary. Change of specific surface area after "consolidation" is neglected for the small thickness of the water film; simultaneously, semiconnected and sealed voids are also neglected. In Dang's study [11], void ratio in empirical calculation methods for coarse-grained soil is replaced by effective void ratio, and the calculation accuracy is improved, but it does not consider the equivalent principle; variation of void ratio is also neglected, so the difference is still inevitable. Therefore, when void ratio is replaced by "equivalent void ratio," the equivalent calculation methods of the seepage coefficient for clay are obtained.

$$
\begin{aligned}
& \because e=e_{\mathrm{e}}+e_{0}=\frac{V_{\mathrm{e}}+V_{0}}{V_{\mathrm{s}}}, \\
& e^{\prime}=\frac{V_{\mathrm{e}}}{V_{\mathrm{s}}+V_{0}}=\frac{V_{\mathrm{e}}}{\left(\left(V_{\mathrm{e}}+V_{0}\right) / e\right)+V_{0}}=\frac{e}{(1+e)\left(V_{0} / V_{\mathrm{e}}\right)+1}, \\
& \quad \text { if } \lambda=\frac{V_{0}}{V_{\mathrm{e}}}=\frac{e_{0}}{e_{\mathrm{e}}}=\frac{e_{0}}{e-e_{0}}, \text { then } e^{\prime}=\frac{e}{\lambda(1+e)+1},
\end{aligned}
$$

where $e$ is the initial void ratio, $e_{\mathrm{e}}$ is the effective void ratio, $e_{0}$ is the ineffective void ratio, $V_{\mathrm{e}}$ is the volume of effective voids $\left(\mathrm{mm}^{3}\right), V_{0}$ is the volume of ineffective voids $\left(\mathrm{mm}^{3}\right), V_{\mathrm{s}}$ is the volume of the soil particle $\left(\mathrm{mm}^{3}\right), e^{\prime}$ is the "equivalent void ratio," and $\lambda$ is the ratio between ineffective and effective void ratios or volumes and is a constant for certain soil.

Substituting equation (1) into the former four formulas in Table 4, the equivalent calculation methods of the seepage coefficient for clay can be obtained preliminarily, which are shown in Table 5 .

Table 5 shows that the parameter $\lambda$ is included in the equivalent calculation methods. Therefore, it is very important to determine $\lambda$. When parameter $\lambda$ is low, it indicates the ineffective void is low, and the calculation method is also suitable for coarse-grained soil. Especially, equivalent calculation methods of the seepage coefficient for clay are the same as those for coarsegrained soil when $\lambda=0$, so it unifies different calculation methods.

4.2. Determination of Parameter $\lambda$. Parameter $\lambda$ depends on the method to determine the volume of ineffective voids, which is equal to that of bound water. The liquid-plastic limit method of macroscopic soil mechanics is often adopted to determine the content of bound water [11, 14], which is shown in Figure 5 and in the following:

$$
\begin{aligned}
& w_{0}= \begin{cases}w_{\mathrm{s}}=w, & 0<w \leq 0.885 w_{\mathrm{P}}, \\
w_{\mathrm{s}}+w_{\mathrm{w}}=0.885 w_{\mathrm{P}}+\left(w-0.885 w_{\mathrm{P}}\right)=w, & 0.885 w_{\mathrm{P}}<w \leq w_{\mathrm{P}}, \\
w, & w_{\mathrm{P}}<w \leq \alpha w_{\mathrm{L}}, 0<\alpha<1, \\
\alpha w_{\mathrm{L}}, & w>\alpha w_{\mathrm{L}}, 0<\alpha<1,\end{cases} \\
& = \begin{cases}w, & 0<w \leq \alpha w_{\mathrm{L}}, 0<\alpha<1, \\
\alpha w_{\mathrm{L}}, & w>\alpha w_{\mathrm{L}}, 0<\alpha<1,\end{cases}
\end{aligned}
$$


TABLE 5: Calculation methods of the seepage coefficient for coarse-grained soil and clay.

\begin{tabular}{lccc}
\hline Name & Calculation methods & Clay \\
& $\begin{array}{c}\text { Coarse-grained soil } \\
\text { Empirical calculation } \\
\text { methods }\end{array}$ & $\begin{array}{c}\text { Effective calculation } \\
\text { methods [11] }\end{array}$ & $\begin{array}{c}\text { Equivalent calculation } \\
\text { methods }\end{array}$ \\
\hline $\begin{array}{l}\text { Seepage coefficient of Terzaghi } \\
\text { Seepage coefficient of IWHR }\end{array}$ & $k=2 e^{2} d_{10}^{2}$ & $k=2\left(e-e_{0}\right)^{2} d_{10}^{2}$ & $k=2 e^{\prime 2} d_{10}^{2}$ \\
Seepage coefficient of Curson-Karman & $k=\left(c_{2} \rho_{\mathrm{wz}} e^{3} / s^{2} \eta(1+e)\right)$ & $k=\left(c_{2} \rho_{\mathrm{wz}}\left(e-e_{0}\right)^{3} / s^{2} \eta\left(1+e-e_{0}\right)\right)$ & $k=\left(c_{2} \rho_{\mathrm{wz}} e^{\prime 3} / s^{2} \eta\left(1+e^{\prime}\right)\right)$ \\
Seepage coefficient of KC & $k=\left(e^{3} / 5(1+e)\right)\left(d_{10} / 6\right)^{2}$ & $k=\left(\left(e-e_{0}\right)^{3} / 5\left(1+e-e_{0}\right)\right)\left(d_{10} / 6\right)^{2}$ & $k=\left(e^{\prime 3} / 5\left(1+e^{\prime}\right)\right)\left(d_{10} / 6\right)^{2}$ \\
\hline
\end{tabular}

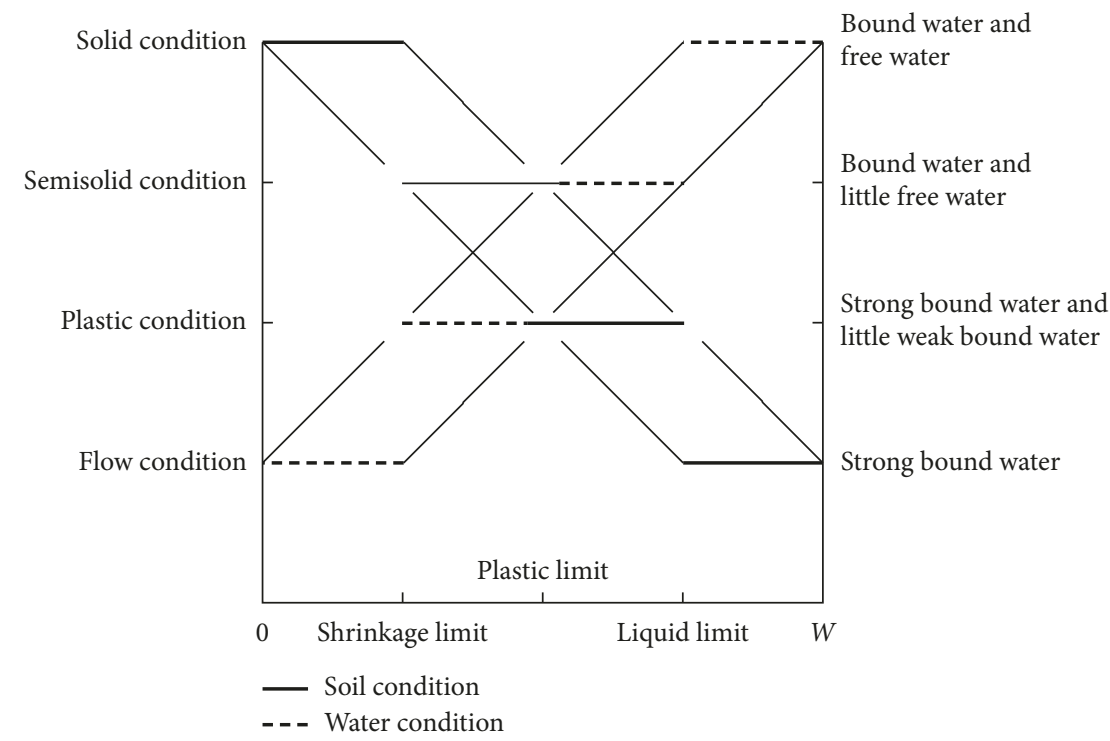

Figure 5: Liquid-plastic limit condition of soil.

where $w_{0}$ is the content of bound water, $w_{\mathrm{s}}$ is the content of strong bound water, $w$ is the moisture content, $w_{\mathrm{P}}$ is the plastic limit, $w_{\mathrm{w}}$ is the content of weak bound water, $\alpha$ is a constant $(0<\alpha<1)$, and $w_{\mathrm{L}}$ is the liquid limit.
Under permeation condition, the moisture content is not the initial one but the saturated moisture content. In Dang's study [11], the relation between saturated moisture content and $\alpha w_{\mathrm{L}}$ is not considered and it is not strict to some extent.

$$
\because e_{0}=\frac{V_{0}}{V_{\mathrm{s}}}=\frac{\left(m_{\mathrm{w} 0} / \rho_{\mathrm{w}}\right)}{\left(m_{\mathrm{s}} / \rho_{\mathrm{s}}\right)}=\frac{\left(w_{0} \cdot\left(m_{\mathrm{s}} / \rho_{\mathrm{w}}\right)\right)}{\left(m_{\mathrm{s}} / \rho_{\mathrm{s}}\right)}= \begin{cases}\frac{\left(w_{\mathrm{sat}} \cdot\left(m_{\mathrm{s}} / \rho_{\mathrm{w}}\right)\right)}{\left(m_{\mathrm{s}} / \rho_{\mathrm{s}}\right)}=\frac{w_{\mathrm{sat}} \cdot \rho_{\mathrm{s}}}{\rho_{\mathrm{w}}}=w_{\mathrm{sat}} \cdot d_{\mathrm{s}}=e, & 0<w_{\mathrm{sat}} \leq \alpha w_{\mathrm{L}}, \\ \frac{\left(\alpha w_{\mathrm{L}} \cdot\left(m_{\mathrm{s}} / \rho_{\mathrm{w}}\right)\right)}{m_{\mathrm{s}} / \rho_{\mathrm{s}}}=\frac{\alpha w_{\mathrm{L}} \cdot \rho_{\mathrm{s}}}{\rho_{\mathrm{w}}}=\alpha w_{\mathrm{L}} \cdot d_{\mathrm{s}}, & 0<\alpha<1,\end{cases}
$$

where $m_{\mathrm{w} 0}$ is the mass of ineffective void water $(\mathrm{g}), \rho_{\mathrm{w}}$ is the density of water $\left(1.0 \mathrm{~g} / \mathrm{cm}^{3}\right), m_{\mathrm{s}}$ is the mass of the soil particle $(\mathrm{g}), \rho_{\mathrm{s}}$ is the density of the soil particle $\left(\mathrm{g} / \mathrm{cm}^{3}\right), w_{\text {sat }}$ is the saturated moisture content, $d_{s}$ is the relative density of the soil particle, and the others are the same as given above.

It can be found that $e_{0}=e$ when $0<w_{\text {sat }} \leq \alpha w_{\mathrm{L}}$; namely, bound water fills the soil void, the effective void is inexistent, and the seepage coefficient is 0. In Dang's study [11], $\alpha$ is 0.9 . In order to verify its suitability, comparison calculations are made in the next section, and the selected values are $0.80,0.85,0.95$, and 1.0; the results show they are appropriate when $\alpha$ is 0.9 .

\section{Evaluation of Equivalent Calculation Methods}

In order to verify the feasibility and accuracy of equivalent calculation methods, three types of clay soils are selected-compacted reconstruction loess (No. 1), soft clay from South China Sea (No. 2), and coastal saline soil from Kuwait (No. 3) $[5,6,11,15,16]$; the correlative parameters are shown in Tables 6 and 7. Based on the calculation formulas in Table 5 (formula 1: Terzaghi; formula 2: IWHR; formula 3: Curson-Karman; formula 4: $\mathrm{KC}$ ), the calculation results 
TABLe 6: The parameter $\lambda$ and equivalent void ratio.

\begin{tabular}{lccccccccc}
\hline Soil no. & $e$ & $d_{\mathrm{s}}$ & $\rho_{\mathrm{w}}\left(\mathrm{g} / \mathrm{cm}^{3}\right)$ & $w_{\text {sat }}(\%)$ & $\alpha$ & $w_{\mathrm{L}}(\%)$ & $e_{0}$ & $\lambda$ & $e^{\prime}$ \\
\hline 1 & 1.08 & 2.72 & 1.0 & 39.7 & 0.9 & 22.0 & 0.539 & 0.813 & 0.4013 \\
2 & 1.933 & 2.65 & 1.0 & 72.9 & 0.9 & 51.5 & 1.228 & 1.743 & 0.3163 \\
3 & 1.074 & 2.49 & 1.0 & 43.1 & 0.9 & 33.0 & 0.740 & 2.211 & 0.1923 \\
\hline
\end{tabular}

TABLE 7: The correlative calculation parameters.

\begin{tabular}{lccccccccc}
\hline Soil no. & $d_{10}(\mathrm{~mm})$ & $d_{20}(\mathrm{~mm})$ & $d_{50}(\mathrm{~mm})$ & $c_{2}$ & $\rho_{\mathrm{WZ}}\left(\mathrm{g} / \mathrm{cm}^{3}\right)$ & $s\left(\mathrm{~cm}^{-1}\right)$ & $\eta(\mathrm{Pa} \cdot \mathrm{s})$ & $C_{\mathrm{F}}(\%)$ & $A_{\mathrm{c}}$ \\
\hline 1 & 0.001 & 0.005783 & 0.0345 & 0.125 & 1.0 & 1739.1304 & $10^{-3}$ & 14.113 & 0.10 \\
2 & 0.001 & 0.002473 & 0.01 & 0.125 & 1.0 & 6000.0 & $10^{-3}$ & 16.988 & 0.42 \\
3 & 0.001 & 0.003086 & 0.008 & 0.125 & 1.0 & 7500.0 & $10^{-3}$ & 14.798 & 0.35 \\
\hline
\end{tabular}

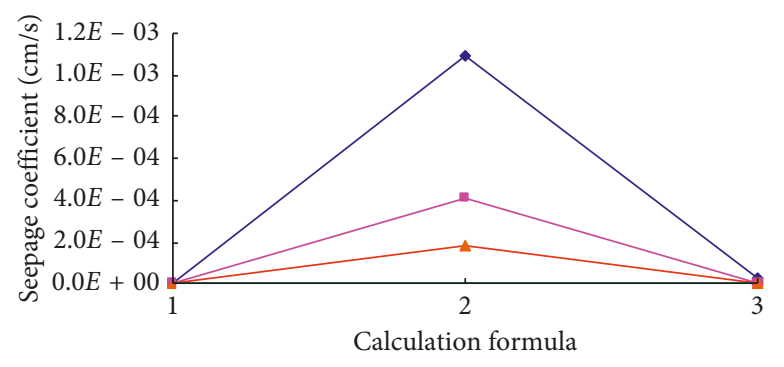

$\rightarrow \begin{aligned} & \text { Empirical calculation method for } \\ & \text { coarse-grained soil }\end{aligned}$
$\rightarrow$ Effective calculation method for clay
$\rightarrow$ Equivalent calculation method for clay
- Test value of seepage coefficient

(a)

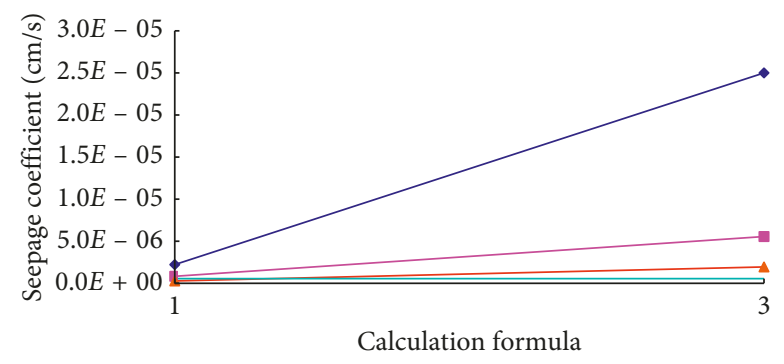

Empirical calculation method for coarse-grained soil

$\rightarrow$ Effective calculation method for clay

^- Equivalent calculation method for clay

_ Test value of seepage coefficient

(b)

Figure 6: Seepage coefficients of compacted reconstruction loess under (a) formulas (1)-(3) and (b) formulas (1) and (3).

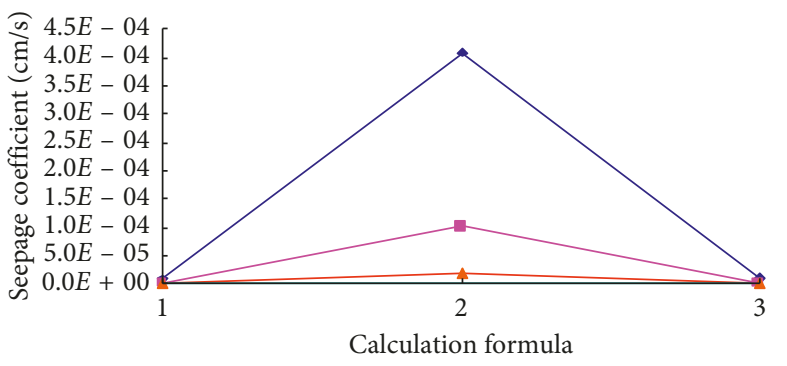

Empirical calculation method for coarse-grained soil

- - Effective calculation method for clay

— Equivalent calculation method for clay

Test value of seepage coefficient

(a)
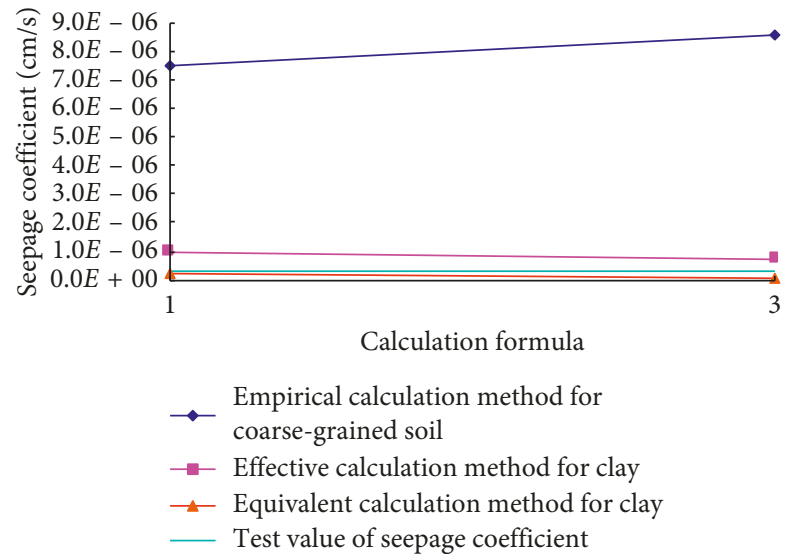

(b)

FIGURE 7: Seepage coefficients of clay from South China Sea under (a) formulas (1)-(3) and (b) formulas (1) and (3).

under different methods can be obtained, which are shown in Figures 6-8 and Table 8.

Table 8 shows that seepage coefficients under different calculation methods have the coherence for every soil, the difference between calculation method for coarse-grained soil and experimental value is the largest, the effective calculation method for clay takes the second place, and the equivalent calculation method for clay is the closest; hence, the superiority of the equivalent calculation method is apparent. In order to evaluate them quantitatively, the 


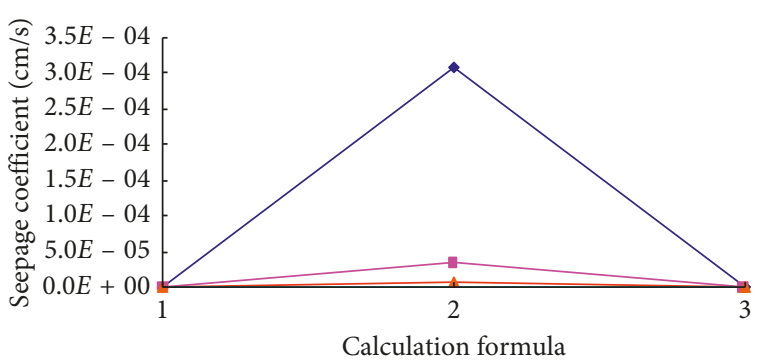

$\rightarrow \begin{aligned} & \text { Empirical calculation method for } \\ & \text { coarse-grained soil }\end{aligned}$
$\rightarrow$ Effective calculation method for clay
$\longleftarrow$ Equivalent calculation method for clay
$\longleftarrow$ Test value of seepage coefficient

(a)
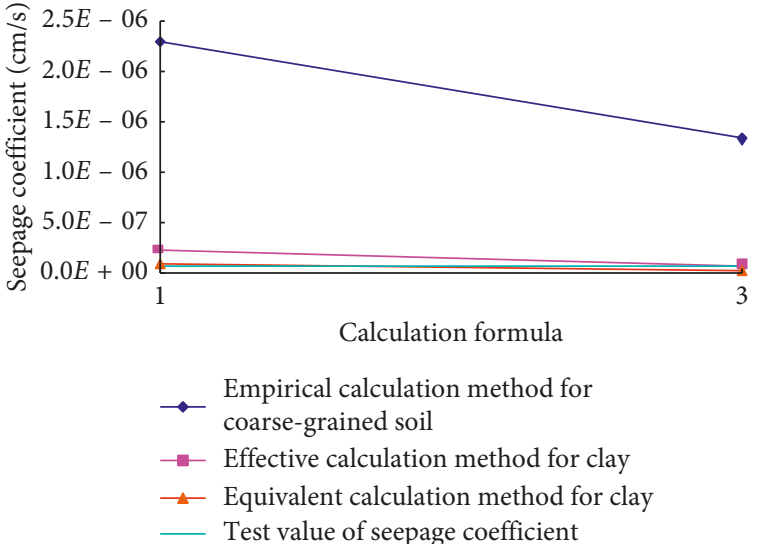

(b)

FIGURE 8: Seepage coefficients of coastal saline soil from Kuwait under (a) formulas (1)-(3) and (b) formulas (1) and (3).

TABle 8: Seepage coefficients of KC under different methods.

\begin{tabular}{|c|c|c|c|}
\hline \multirow{3}{*}{ Calculation methods } & \multicolumn{3}{|c|}{ Soil } \\
\hline & \multicolumn{3}{|c|}{ Seepage coefficient $(\mathrm{cm} / \mathrm{s})$} \\
\hline & No. 1 & No. 2 & No. 3 \\
\hline Empirical calculation methods for coarse-grained soil & $3.365 * 10^{-9}$ & $1.368 * 10^{-8}$ & $3.318 * 10^{-9}$ \\
\hline Effective calculation methods for clay & $5.708 * 10^{-10}$ & $1.142 * 10^{-9}$ & $1.552 * 10^{-10}$ \\
\hline Equivalent calculation methods for clay & $2.562 * 10^{-10}$ & $1.336 * 10^{-10}$ & $3.313 * 10^{-11}$ \\
\hline Experimental value & $4.2 * 10^{-7}$ & $2.7 * 10^{-7}$ & $6.48 * 10^{-8}$ \\
\hline
\end{tabular}

multiples between them are calculated; the results show that, for every soil, (1) the difference between calculation method for coarse-grained soil and experimental value is a little larger, and the minimal and maximal difference in orders of magnitude is one and three; (2) the difference between seepage coefficient of IWHR in every method and experimental value is also a little larger, and the minimal and maximal difference in orders of magnitude is two and three; and (3) seepage coefficients of Terzaghi and Curson-Karman in every method are closer to experimental values, and the coefficients of the equivalent calculation method are the closest, that is, they are equal approximately. Therefore, the equivalent calculation method of the seepage coefficient for clay is feasible, and it is accurate to some extent.

From Table 8, it can be found that seepage coefficients of $\mathrm{KC}$ are all low under different methods for every soil, and the difference between results calculated by the equivalent method and experimental value is three orders of magnitude, so it is not suitable for calculating the seepage coefficient for clay. In addition, results (shown in Table 9) calculated by the Mesri equation in Table 3 are also close to experimental values, they have the same order of magnitude as well, and they are also equal approximately. Therefore, the recommended methods to calculate the seepage coefficient for clay are the Mesri equation and equivalent calculation method of Terzaghi or Curson-Karman.
TABLE 9: Seepage coefficients of clay based on the Mesri equation.

Calculation method

Soil Seepage coefficient $(\mathrm{cm} / \mathrm{s})$

\begin{tabular}{|c|c|c|}
\hline & $\begin{array}{l}\text { Mesri } \\
\text { equation }\end{array}$ & $\begin{array}{l}\text { Experimental } \\
\text { value }\end{array}$ \\
\hline $\begin{array}{l}\text { Compacted reconstruction } \\
\text { loess }\end{array}$ & $1.532 * 10^{-7}$ & $4.2 * 10^{-7}$ \\
\hline Soft clay from South China Sea & $2.696 * 10^{-7}$ & $2.7 * 10^{-7}$ \\
\hline Coastal saline soil from Kuwait & $5.463 * 10^{-8}$ & $6.48 * 10^{-8}$ \\
\hline
\end{tabular}

\section{Conclusions}

The following conclusions can be obtained:

(1) Particle size and porosity are the main influencing factors for clay permeability. Under certain porosity, specific surface area and bound-water volume are large when the particle size is small, thus lengthening the permeation route along the permeation direction and reducing the void opening perpendicular to the permeation direction. Similarly, under certain particle size, void opening is also small when the porosity is low. These effects consume the permeation energy and compress the permeation space, thus reducing the clay permeability.

(2) Seepage, permeation, and effective permeation are three different concepts; groundwater permeates in 
clay via the effective void mainly and the effective permeation is the actual current, while it permeates via voids in coarse-grained soil. For certain soil, the increasing sequence of permeability coefficients is the seepage coefficient, permeation coefficient, and effective permeation coefficient.

(3) Based on bound-water "consolidation," clay can be equivalent to coarse-grained soil in terms of soil structure and permeation mechanism. The void ratio after "consolidation" is not the simple subtraction of initial and ineffective void ratios, and introduction of "equivalent void ratio" unifies the calculation methods of the seepage coefficient for clay and coarse-grained soil.

(4) Bound-water content can be calculated by the liquidplastic limit method, the maximal value is about 0.9 time the size of liquid limit, and the saturated moisture content needs to be considered certainly.

(5) The feasible methods to calculate the seepage coefficient of clay are the Mesri equation and the equivalent Terzaghi or Curson-Karman method because their calculation results are the closest to experimental values.

\section{Data Availability}

The data used to support the findings of this study are included within the article.

\section{Disclosure}

An earlier version of this article was presented as an abstract in "Proceedings of the International Conference on GeoMechanics, Geo-Energy and Geo-Resources (IC3G 2018).”

\section{Conflicts of Interest}

The authors declare that there are no conflicts of interest regarding the publication of this paper.

\section{Acknowledgments}

Thanks are due for all relevant material providers and authors cited, especially the academic thought, research idea, and methods shared in Dang's study. This study was supported by the National Key R\&D Plan Special Project of China (Grant No. 2017YFC0805406) and Beijing Municipal Natural Science Foundation (Grant No. 8161001).

\section{References}

[1] G. Mesri, L. Kwan, O. Dominic et al., "Settlement of embankments on soft clays," Geotechnical Special Publication, vol. 1, no. 40, pp. 8-56, 1994.

[2] L. N. Reddi and S. Thangavadivelu, "Representation of compacted clay minifabric using random networks," Journal of Geotechnical Engineering, vol. 122, no. 11, pp. 906-913, 1996.
[3] J. He and J. Y. Shi, "Calculation of saturated permeability coefficient of bentonite," Chinese Journal of Rock Mechanics and Engineering, vol. 26, no. 2, pp. 3920-3925, 2007.

[4] J. W. Liang and Y. G. Fang, "Experimental study of seepage characteristics of tiny-particle clay," Chinese Journal of Rock Mechanics and Engineering, vol. 29, no. 6, pp. 1222-1230, 2010.

[5] H. Liao, L. Su, Z. Li, Y. Pan, and H. Fukuoka, "Testing study on the strength and deformation characteristics of soil in loess landslides," in Proceedings of 10th International Symposium on Landslides and Engineered Slopes, pp. 443-447, CRC PressTaylor\&Francis Group, Xi'an, China, June 2008.

[6] H. J. Liao, T. Li, and J. B. Peng, "Study of strength characteristics of high and steep slope landslide mass loess," Rock and Soil Mechanics, vol. 32, no. 7, pp. 1939-1944, 2011.

[7] X. Y. Wang and C. L. Liu, "Discussion on permeability law of deep clayey soil," Chinese Journal of Geotechnical Engineering, vol. 25, no. 3, pp. 308-312, 2003.

[8] X. D. Zhang, Y. Zhang, B. Zhang et al., "Optimization and improvement of Sweden Slice Method considering the pore water pressure," Chinese Quarterly of Mechanics, vol. 34, no. 4, pp. 643-649, 2013.

[9] Y. Zhang, T. L. Chen, Z. F. Wang et al., "An equivalent method for calculating the seepage coefficient of clay based on solidified micro-bound water," Chinese Journal of Rock Mechanics and Engineering, vol. 37, no. 4, pp. 1004-1010, 2018.

[10] Y. F. Deng, S. Y. Liu, D. W. Zhang et al., "Comparison among some relationships between permeability and void ratio," Northwestern Seismological Journal, vol. 33, pp. 64-66, 2011.

[11] F. N. Dang, H. W. Liu, X. W. Wang et al., "Empirical formulas of permeability of clay based on effective pore ratio," Chinese Journal of Rock Mechanics and Engineering, vol. 34, no. 9, pp. 1909-1917, 2015.

[12] H. Komine, "Predicting hydraulic conductivity of sandbentonite mixture backfill before and after swelling deformation for underground disposal of radioactive wastes," Engineering Geology, vol. 114, no. 3-4, pp. 123-134, 2010.

[13] H. Tanaka, D. R. Shiwakoti, N. Omukai, F. Rito, J. Locat, and M. Tanaka, "Pore size distribution of clayey soils measured by mercury intrusion porosimetry and its relation to hydraulic conductivity," Soils and Foundations, vol. 43, no. 6, pp. 63-73, 2003.

[14] D. S. Cui, W. Xiang, L. J. Cao et al., "Experimental study on reducing thickness of absorbed water layer for red clay particles treated by Ionic Soil Stabilizer," Chinese Journal of Geotechnical Engineering, vol. 32, no. 6, pp. 944-949, 2010.

[15] R. Ananth, Geotechnical Investigation-Factual Report of Trial Embankment of Bubiyan Seaport Phase-1 Stage-1 Road, Bridge and Soil Improvement (No. 200702 109-TM), Gulf Inspection International Company, Kuwait City, Kuwait, 2008.

[16] H. M. Yang, "Test investigations of the permeability behavior of the soft clay in the South China Sea," M.S. thesis, Wuhan University of Technology, Wuhan, China, 2012. 


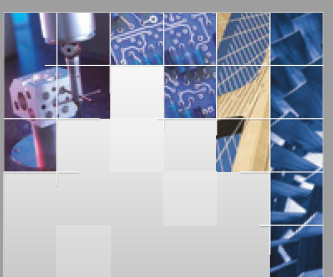

\section{Enfincering}
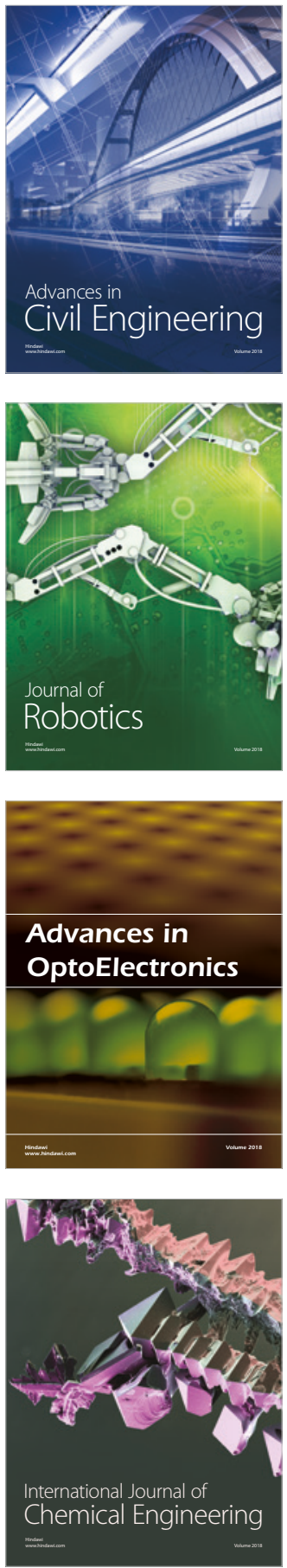

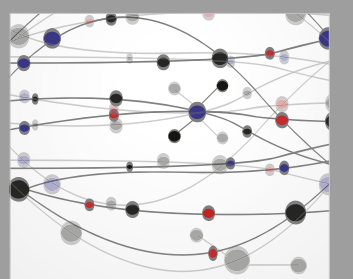

\section{Rotating \\ Machinery}

The Scientific World Journal

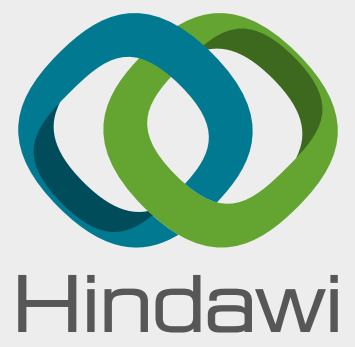

Submit your manuscripts at

www.hindawi.com
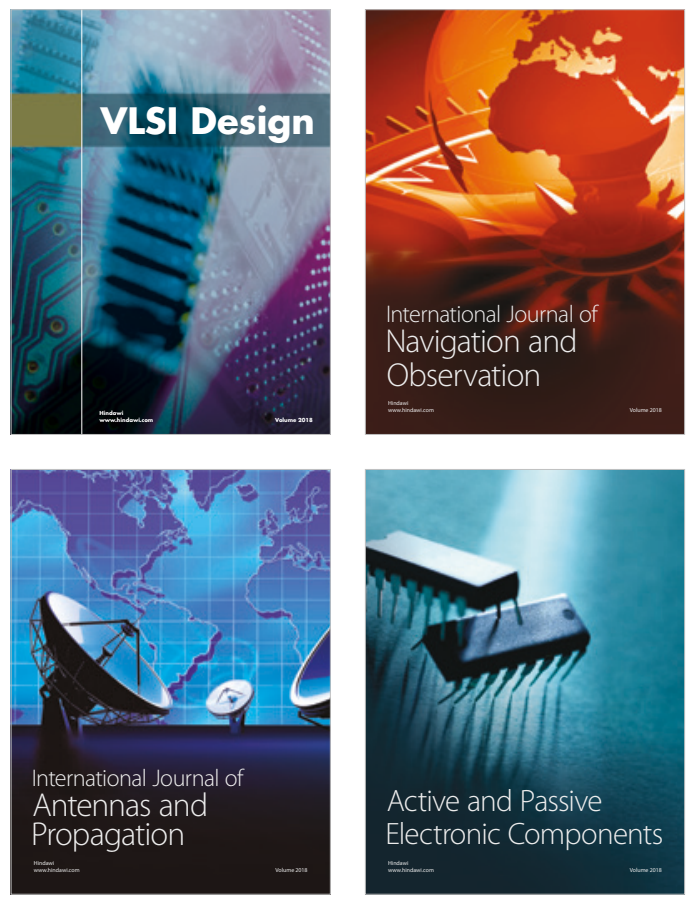
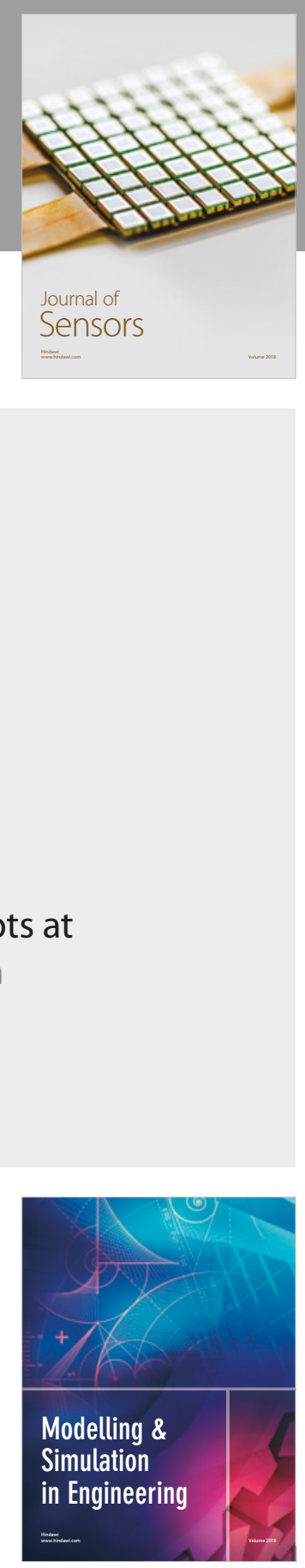

\section{Advances \\ Multimedia}
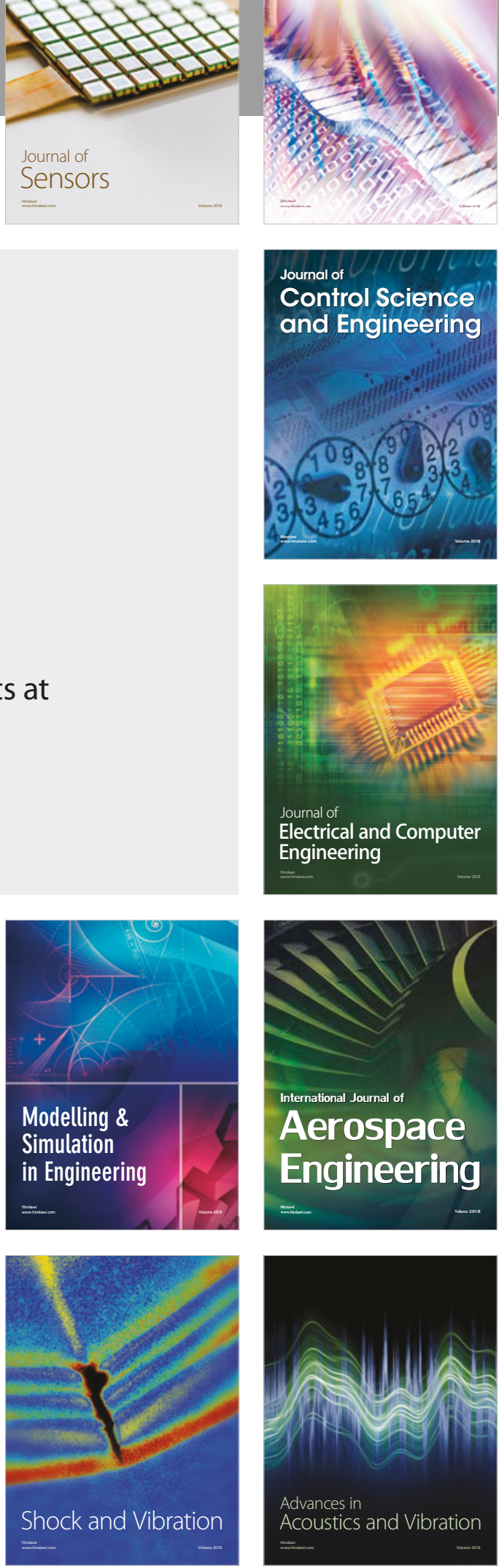